\title{
Performance Evaluation of Effluent Treatment Plant for Textile Mill at Ramtek, MS, India
}

\author{
Swati A. Karekar ${ }^{1}$, M. P. Bhorkar², Dr. V. P. Thergaonkar \\ 1. IVSem (M.Tech Env. Engg), GHRCE, Nagpur \\ 2. Asst. Prof. (Civil Engg., Department), GHRCE, Nagpur \\ 3. Ex. NEERI Scientist, Enviro Techno Consult, Nagpur
}

\begin{abstract}
The present study has been undertaken to evaluate performance efficiency of an Effluent Treatment Plant (ETP) of a Textile industry located at Ramtek, Nagpur (Maharashtra). An existing ETP is operating on biological treatment method (extended aeration activated sludge system) followed by tertiary treatment plant (R.O), with an average inflow of $30 \mathrm{~m}^{3} / \mathrm{hr}$. Wastewater is analyzed for major parameters such as $\mathrm{pH}$, Chemical Oxygen Demand (COD), Biological Oxygen Demand (BOD), Total Dissolved Solid (TDS), Total Solid (TS), Total Suspended Solid (TSS) and Alkalinity. The effluent samples were collected from each units of ETP on a monthly basis for a certain period. A jar test was also conducted to determine the optimum dose of alum with respect to COD removal. After an experimentation, it was found at 400 to $500 \mathrm{mg} / \mathrm{l}$ dose of alum $42.48 \%$ COD reduction was achieved. The COD, BOD, TS and alkalinity after biological treatment reduces significantly, except TDS \& TSS having very low reduction of $44 \%$ \& $45 \%$ respectively. Overall treatment \& analysis for treated effluent (from RO) describes, most of all the parameters were found within the permissible limit of Maharashtra Pollution Control Board. (MPCB)
\end{abstract}

Keywords: ETP, Chemical Parameters, \% removal Efficiency, optimum dose, MPCB

\section{Introduction}

The textile industry is one of the leading sectors in the Indian economy as it contributes nearly $14 \%$ to the total industrial production. The untreated textile wastewater cause rapid depletion of dissolved oxygen due to its high BOD value, if it is directly discharge into the surface water. The effluent with high levels of BOD and COD values are highly toxic for biological life. The high alkalinity and traces of chromium which is employed in dyes adversely affect the aquatic life and also interferes with the biological treatment process (Desai P. A. et al., 2011). Wastewater contaminated by dyes represents a relevant issue associated with several industries. Dyes, even at very low concentrations, reduce wastewater transparency and oxygen solubility and are often toxic and recalcitrant; moreover, these chemicals are toxic, carcinogenic or mutagenic for various organisms (P. U. Singare et al., 2014). Azo dyes are the most widely used dyes in industry \& commonly used for cotton dyeing (S. Sen et al.,). Textile wastewater is one of the industrial wastewater which is very difficult to deal, the difficulty stems is due to large variability of characteristics in those wastewater (Sheng et al.,). India an average textile mill producing $60 \times 10^{4} \mathrm{~m}$ of fabric per day is likely to discharge approximately 1.5 MLD of effluent (G.Gnanapragasam. et. al.). The quality of such effluent can be analyzed by their physico-chemical and biological analysis. Monitoring of the environmental parameters of the effluent would allow having, at any time, a precise idea on performance evaluation of ETP and if necessary, appropriate measures may be undertaken to prevent adverse impact on environment (sumitkumar Patel etal.). The efficiency of individual units of an effluent treatment plants determines the overall performance of the plant and the final effluent quality (Khan et al.). Textile industry is a water intense industry consumes large quantities of water and thus produces large volume of wastewater during its manufacturing steps like dyeing, mercerizing, bleaching, and finish process.

\subsection{Study area}

\section{Materials And Methods}

The study was carried out for ETP of a textile mill at Ramtek near Nagpur city, having latitude \& longitude of $21^{\circ} 18^{\prime} 56.95^{\prime} \mathrm{N}$ and $79^{\circ} 29^{\prime} 19.01^{\prime} \mathrm{E}$ respectively. The Total area occupied by the mill is $44.6 \mathrm{ha}$, out of which 0.104ha is allotted for Effluent Treatment Plant (ETP), 5 ha for Power Plant and remaining for textile unit, residential colony, stores etc. Water is supplied to the mill from Khindsi Lake and Canal near Ramtek. About $800-900 \mathrm{~m}^{3} / \mathrm{d}$ water is required for manufacturing process, and the total generation of waste water from the textile mill is about $700-800 \mathrm{~m}^{3} / \mathrm{d}$. Recovered quantity of water after tertiary treatment varies between 400 and $670 \mathrm{~m}^{3} / \mathrm{d}$. 


\subsection{Requirements}

All the glassware, burette and pipettes were first cleaned with tap water thoroughly and finally with deionized distilled water. The chemicals and reagents were used for analysis were analytical reagent grade. The procedure for analysis or calculating the different parameters were conducted in the laboratory.

\subsection{Industrial Effluent Sampling and Preservation}

An existing ETP at Ramtek comprises of chemical treatment in which Poly aluminum Chloride (PAC) and lime was used as a coagulant followed by biological treatment which is operating on extended aeration activated sludge system along with a tertiary treatment plant where Reverse Osmosis (RO) unit is provided. The effluent samples were collected from each units of ETP (equalization, flocculation, PST [Primary Settling Tank], Aeration, SST [Secondary Settling Tank] and RO) on monthly basis for a period of Nov-13 to Apr-14. Samples were collected in a plastic bottle, before collecting it was thoroughly cleaned with hydrochloric acid and washed with tap water to render free of acid. The sample bottle was then labeled and its $\mathrm{pH}$ was also checked at site with $\mathrm{pH}$ paper. Until the analysis was over the effluent samples were preserved below $4^{\circ} \mathrm{C}$.

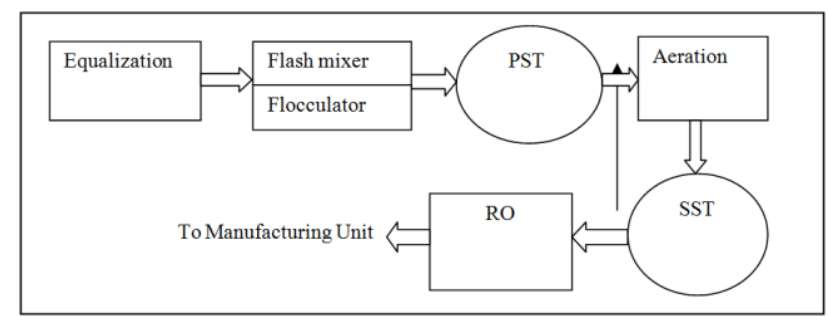

Fig 1. Flow Chart of ETP

\subsection{Physico-chemical study}

The collected samples were analyzed for pH, Total Dissolved Solids (T.D.S), Total Suspended Solids (T.S.S), Total Solids (T.S), Biological Oxygen Demand (B.O.D), Chemical Oxygen Demand (C.O.D) and Alkalinity

\section{Result and Discussion}

The experimental data on physico-chemical properties of effluent from different units of ETP is presented in the Table. No.1. In present study with an average flow of $30 \mathrm{~m}^{3} / \mathrm{hr}, \mathrm{pH}$ value was found to be very high at equalization (13.1) due to use of sodium hydroxide in manufacturing which was brought to neutral at RO (7.0). By providing tertiary treatment the percentage removal efficiency in the TS, TDS, TSS and COD was $96 \%, 97 \%, 88 \%$ and $98 \%$ respectively, whereas for BOD and alkalinity it was found $99 \%$ reduction. The efficiency after biological treatment for COD, BOD and alkalinity was $88 \%, 98 \%$ and $93 \%$, whereas for TDS and TSS it was found $44 \& 45 \%$ respectively. After chemical treatment the percentage removal efficiency in TS was 19 to $30 \%$ which was due to colloidal solid present in effluent, TSS was 31 to $41 \%$, and very less removal in TDS was observed having 17 to $33 \%$, average TSS \& TDS was found to be 38 \& $24 \%$ respectively, whereas the reduction in COD was found to be insignificant having $36 \%$ reduction.

Table 1. Physico-Chemical Properties of Effluent Samples Collected from various Units of ETP

\begin{tabular}{|c|c|c|c|c|c|c|c|c|}
\hline \multirow{2}{*}{$\begin{array}{l}\text { Physico- } \\
\text { chemical } \\
\text { properties }\end{array}$} & \multicolumn{8}{|c|}{ Units } \\
\hline & Months & Equalization & Flocculation & PST & Aeration & SST & RO & \% Removal \\
\hline \multirow{6}{*}{ pH } & Nov-13 & 13.0 & -- & -- & 7.8 & 7.8 & -- & -- \\
\hline & Dec-13 & \multirow{2}{*}{\begin{tabular}{|l|}
13.1 \\
12.8
\end{tabular}} & \multirow{2}{*}{$\begin{array}{c}11.6 \\
67\end{array}$} & 7.4 & 7.5 & 8.0 & 7.0 & -- \\
\hline & Jan-14 & & & 7.3 & 8.7 & 8.6 & 7.6 & -- \\
\hline & Feb-14 & 12.9 & $\begin{array}{l}0.1 \\
7.3 \\
\end{array}$ & 7.6 & 8.3 & 8.5 & 7.2 & -- \\
\hline & Mar-14 & \multirow{2}{*}{$\begin{array}{l}13.1 \\
12.9\end{array}$} & 10.5 & 7.8 & 9.1 & 9.3 & 7.7 & -- \\
\hline & Apr-14 & & 7.5 & 7.8 & 8.2 & 8.3 & 7.1 & -- \\
\hline \multirow{6}{*}{ TS } & Nov-13 & & -- & -- & 10200 & 9677 & -- & 37 up to sst \\
\hline & Dec-13 & \multirow{2}{*}{$\begin{array}{l}21340 \\
14240\end{array}$} & 16780 & 14920 & 19860 & 11580 & 680 & 96 \\
\hline & Jan-14 & & 13860 & 10480 & 9180 & 8480 & 560 & 96 \\
\hline & Feb-14 & \multirow{2}{*}{$\begin{array}{l}12180 \\
13680\end{array}$} & \multirow{2}{*}{$\begin{array}{l}10940 \\
13360\end{array}$} & 9840 & 8880 & 8240 & 420 & 96 \\
\hline & Mar-14 & & & 10980 & 9340 & 9420 & 300 & 97 \\
\hline & Apr-14 & 14660 & 13820 & 11040 & 9920 & 9680 & 400 & 97 \\
\hline & Nov-13 & 15200 & -- & -- & 9800 & 9600 & -- & 36 up to sst \\
\hline & Dec-13 & 20620 & 15740 & 13700 & 10320 & 11520 & 580 & 97 \\
\hline & Jan-14 & 13560 & 13360 & 9740 & 8800 & 8260 & 440 & 96 \\
\hline TDS & Feb-14 & 11560 & 10500 & 9520 & 8640 & 8080 & 340 & 97 \\
\hline & Mar-14 & 13080 & 12820 & 10600 & 9040 & 9160 & 420 & 96 \\
\hline & Apr-14 & 14020 & 13300 & 10600 & 9660 & 9500 & 320 & 97 \\
\hline Physico- & & & & Units & & & & \\
\hline $\begin{array}{l}\text { chemical } \\
\text { properties }\end{array}$ & Months & Equ & Floc & PST & Aera & SST & RO & $\begin{array}{l}\% \\
\text { Removal }\end{array}$ \\
\hline COD & Nov-13 & 4400 & -- & -- & 152 & 132 & -- & 97 up to sst \\
\hline
\end{tabular}




\begin{tabular}{|c|c|c|c|c|c|c|c|c|}
\hline & Dec-13 & 3040 & 2540 & 2820 & 1240 & 60 & 40 & 98 \\
\hline & Jan-14 & 2120 & 1640 & 1076 & 714 & 280 & 28 & 98 \\
\hline & Feb-14 & 2000 & 1482 & 1440 & 1200 & 488 & 48 & 97 \\
\hline & Mar-14 & 3060 & 1960 & 1176 & 1200 & 560 & 48 & 98 \\
\hline & Apr-14 & 4460 & 2900 & 2720 & 1540 & 224 & 48 & 98 \\
\hline \multirow{6}{*}{ BOD } & Nov-13 & 1160 & -- & -- & 65 & 15 & -- & 98 up to sst \\
\hline & Dec-13 & 920 & 1200 & 610 & 520 & 24 & 14 & 98 \\
\hline & Jan-14 & 1680 & 1480 & 980 & 80 & 56 & 4 & 99 \\
\hline & Feb-14 & 920 & 760 & 980 & 520 & 120 & 13 & 98 \\
\hline & Mar-14 & 880 & 680 & 540 & 200 & 120 & 2 & 99 \\
\hline & Apr-14 & 1100 & 960 & 700 & 560 & 224 & 11 & 99 \\
\hline \multirow{6}{*}{ Alkalinity } & Nov-13 & 7800 & -- & -- & 865 & 900 & -- & 98 up to sst \\
\hline & Dec-13 & 14400 & 1100 & 1140 & 840 & 650 & 96 & 98 \\
\hline & Jan-14 & 11600 & 990 & 960 & 885 & 700 & 80 & 99 \\
\hline & Feb-14 & 14000 & 1130 & 1100 & 900 & 910 & 75 & 98 \\
\hline & Mar-14 & 2300 & 840 & 1390 & 2440 & 980 & 60 & 99 \\
\hline & Apr-14 & 14400 & 1360 & 1320 & 832 & 1072 & 84 & 99 \\
\hline
\end{tabular}
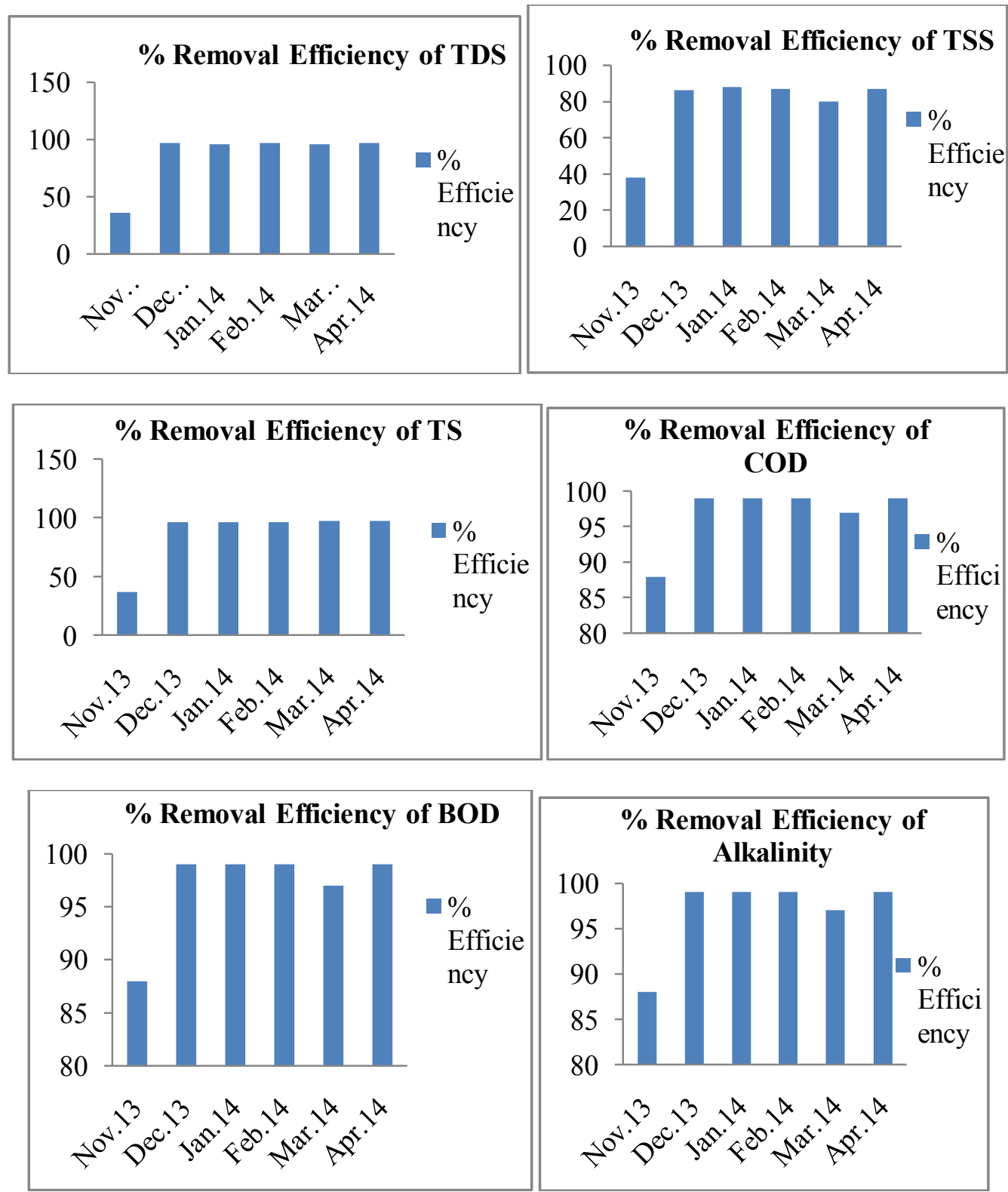

These graphs shows overall \% removal efficiency of all the parameters for treated effluent

A jar test was conducted to determine optimum dose of alum with respect to COD removal. 10\% alum solution was prepared $\&$ added at different dose to $500 \mathrm{ml}$ of 17 number of sample by increasing $0.5 \mathrm{ml}$ dose of alum solution in each sample. After an experiment it was found at 400-500 mg/l dose of alum 42.48\% COD reduction was achieved. Also design for biological system was carried out with flow rate of $30 \mathrm{~m}^{3} / \mathrm{hr}$ considering inlet BOD $700 \mathrm{mg} / \mathrm{l}$ in aeration tank as ETP comprises of 3 aeration tank of known capacity, by trial \& error of F/M (Food to Micro-organism) and MLSS (Mixed Liquor Suspended Solid) and all the parameters $\{$ HRT 
(Hydraulic Retention Time), volumetric loading, SOR (Surface overflow rate)\} was calculated and was found within the design criteria of activated sludge process.

\section{Conclusion}

After estimation it was found, only one aeration tank will be enough to meet the design criteria, hence the other two available tanks can be used for equalization which is necessary at the mill. Removal efficiency for physico-chemical properties in chemical treatment was less than $50 \%$ of their original values, due to improper flow \& incorrect dosing of chemicals.

By providing RO plant characteristic of effluent was brought within the limit of MPCB. And thereby industry is practicing for water conservation by reuse \& recycle of treated wastewater, in the manufacturing process for washing floors \& equipments.

\section{References}

[1] Desai P.A. and Kore V.S.(2011).’Performance Evaluation of Effluent Treatment Plant for Textile Industry in Kolhapur of Maharashtra" Universal Journal of Research \& Technology1, pp 560-565.

[2] P. U. Singare, S. S. Dhabarde, (2014) “ Pollution discharge Scenario of Dyeing Industries along Dombivali Industrial Belt of Mumbai, India", International Letters of Chemistry, Physics and Astronomy 3 (2014) 48-55.

[3] S. Sen and G.N. Demirer.( 2003) "Anaerobic Treatment of Synthetic Textile Wastewater containing a Reactive Azo Dye". J. Environ. Eng. 2003.129: pp. 595-601.

[4] Sheng H. Lin. (1994) “Continuous Treatment Of Textile Water By Ozonation And Coagulation”. J. Environ. Eng. 1994.120: pp.437-446.

[5] G. Gnanapragasamet, M. Senthilkumar, V. Arutchelvan, T.Velayutham, S.Nagarajan.(2011). "Bio-Kinetic analysis on treatment of textile dye wastewater using anaerobic batch reactor".Bioresource Technology 102. pp. 627-632 .

[6] Sumitkumar Patel, Dr. Anita Rajor, Dr. Bharat P. Jain, Payal Patel (2013) "Performance Evalutation of Effluent Treatment Plant of Textile Wet Processing Industry:mA case study of Narol Textile Cluster, Ahmedabad, Gujarat”. IJESIT, Volume 2, pp290 - 296.

[7] B. Ramesh Babu, A.K. Parande, S. Raghu, and T. Prem Kumar(2007).“Cotton Textile Processing: Waste Generation and Effluent Treatment". The journal of cotton science 11, pp. 141-15

[8] MohidusSamad Khan, Shoeb Ahmed, Alexandra E. V. Evans, Matthew Chadwick.(2009). "Methodology for Performance Analysis of Textile Effluent Treatment Plants in Bangladesh". Chemical engineering research bulletin 13, pp 61-66.

[9] Ruey-Fang Yul, Ho-Wen Chen, Wen-Po Cheng, and Peng-Han Hsiehet.al.(2009). "Dosage Control of the Fenton Process for Color Removal of Textile Wastewater Applying ORP Monitoring and Artificial Neural Networks". J. Environ. Eng. 2009.135: pp. 325-33

[10] Ram S. Lokhande, Pravin U. Singare, Deepali S. Pimple (2011) "Study on Physico-Chemical Parameter of Waste Water Effluent from Taloja Industrial Aera of Mumbai, India”, International Journal of Ecosystem 2011;1(1): pp 1-9. 8.

[11] RadhaGoyal, T.R.Sreekrishnan, MukeshKhare, SushilYadav and Meha Chaturvedi.(2010). "Experimental Study on Color Removal from Textile Industry Wastewater Using the Rotating Biological Contactor". Asce 14 pp240-245. 